\title{
APP Interface Design of Qiang People's Silver Jewelry Based on User Experience
}

\author{
Wanyu Zhang \\ College of Fashion and Design Art \\ Sichuan Normal University \\ Chengdu, China
}

\author{
Mengqian Liu \\ College of Fashion and Design Art \\ Sichuan Normal University \\ Chengdu, China
}

\begin{abstract}
In order to integrate the strategic thinking of combining "Mobile Internet" and "Productive Protection of Qiang people's silver jewelry" into the design of APP, an APP interface that is more suitable for mass consumption and aesthetic needs is designed. From the perspective of user experience and cognitive psychology, it analyzed the factors that influence the design of the APP interface, constructed the basic model of the APP interface design, proposed that the design of Qiang people's silver jewelry APP interface should be based on the user's cognitive psychology and user experience, so as to achieve that visual presentation was reasonable, the interface interaction was humanized and the operation experience was diversified. It also completed the design program and implementation of the APP interface design, and verified the validity of the user experience and cognitive requirements on the APP interface design.
\end{abstract}

Keywords-Qiang people's silver jewelry; user experience; cognitive psychology; interface design

\section{INTRODUCTION}

With the continuous development of the mobile Internet and mobile intelligent terminals, digital survival has gradually infiltrated into human life and has been favored by the public, and then APP design has also become one of the most cutting-edge design types in the design field. Dennis McQuire, a communication scientist, once stated: "The emergence of media has brought new cultural forms that are far away from people and even made them become the part of people's daily cultural life quickly [1]." The APP interface design not only stays at the functional level and visual level, but also should be further studied from the perspective of user cognitive psychology and user experience, so that the visual presentation is rationalized, the interface interaction is humanized, and the operation experience is diversified, providing users with a better emotional experience.

\section{THE USERS COGNITIVE PSYCHOLOGY ANALYSIS OF QIANG PEOPLE'S SILVER JEWELRY APP}

Cognition is the whole process of transformation, reduction, interpretation, storage, recovery and use of sensory input, which mainly includes the ability of experience cognition, behavior cognition and emotion cognition [2]. Cognition can change our emotions, while emotions can also affect our cognition, especially some of the more distinct emotions. Cognition can affect our behavior, while the behavior can also affect emotion and cognition. The Qiang people live in high altitude areas, and then they want to be able to get close to the heavens and long for survival. Therefore they are called "the nation on clouds". The Qiang people combined silver jewelry with national sentiment, designed and produced a series of exquisite craftsmanship and rich ethnic silver jewelry, showing people a spiritual world with rich connotations and spreading them among the people.

\section{A. Experience Recognition}

Experience cognition originates from the basic elements of life. It generates cognitive mappings for users in the APP, that is, the product system model matches the user's mental model, and its degree determines the cognition depth of new things [3]. The Qiang people consider themselves as a nation on the clouds, and then they carve clouds on the hair stick. The clouds symbolize good luck, safe and happiness, so this type of hair stick is called wishful hair stick. People have different value orientations and modes of thinking under different ideologies, so only the design of users' real feelings and behaviors can cause emotional resonance.

\section{B. Behavioral Cognition}

Many behaviors can support or reinforce our existing cognition. Cognition not only determines the way that we feel things, but also has an important effect on our behavior. The design of behavioral level is related to the function and ease of use of products [4]. Works that can make people produce attention; can influence people's visual cognition process. Every year, the Qiang people would worship the gods, and then the colors of blue skies with white clouds are very spectacular and have strong contrast. For the clouds flowing in the sky, the Qiang people are inspired from them, to create beautiful patterns in accordance with the image of the clouds. The famous "Clouds and clouds shoes" is a representative work, and the pattern on "Clouds and clouds shoes" is the colorful clouds on the horizon. Therefore, in the design of the APP interface, graphic symbols must have visual impact and visual appeal, motivating people to do things that are consistent with their goals. 


\section{Emotion Cognition}

Cognition not only determines the way that we feel things, but also plays an important role in our behavior. Emotion is an inner experience, which can change emotion. In the past, most studies more focused on usability, transformed usability information into designs, while now it more emphasizes on users' using emotion and interactive experiences [5]. Moreover, our emotions depend on our cognition to a great extent. About the unique apron silver collar button of Qiang people, there is a beautiful love story: a pair of young men and women in the same village fell in love. Once they both went to the mountain to cut firewood, then they saw a dense cluster of rhododendrons not far from them. The young man was touched by the scene, so he took a very bright azalea and inserted the flower in the girl's collar button. The girl asked about the reason, but the young man smiled without replying, just said: "As long as you will remember me forever." From then on, the custom of inserting azaleas on the collar buttons was popular in the folk. When seeing the apron silver collar button with azalea, people will think of this love story. Therefore, the design of the APP interface should reach an emotional exchange and resonance with the users.

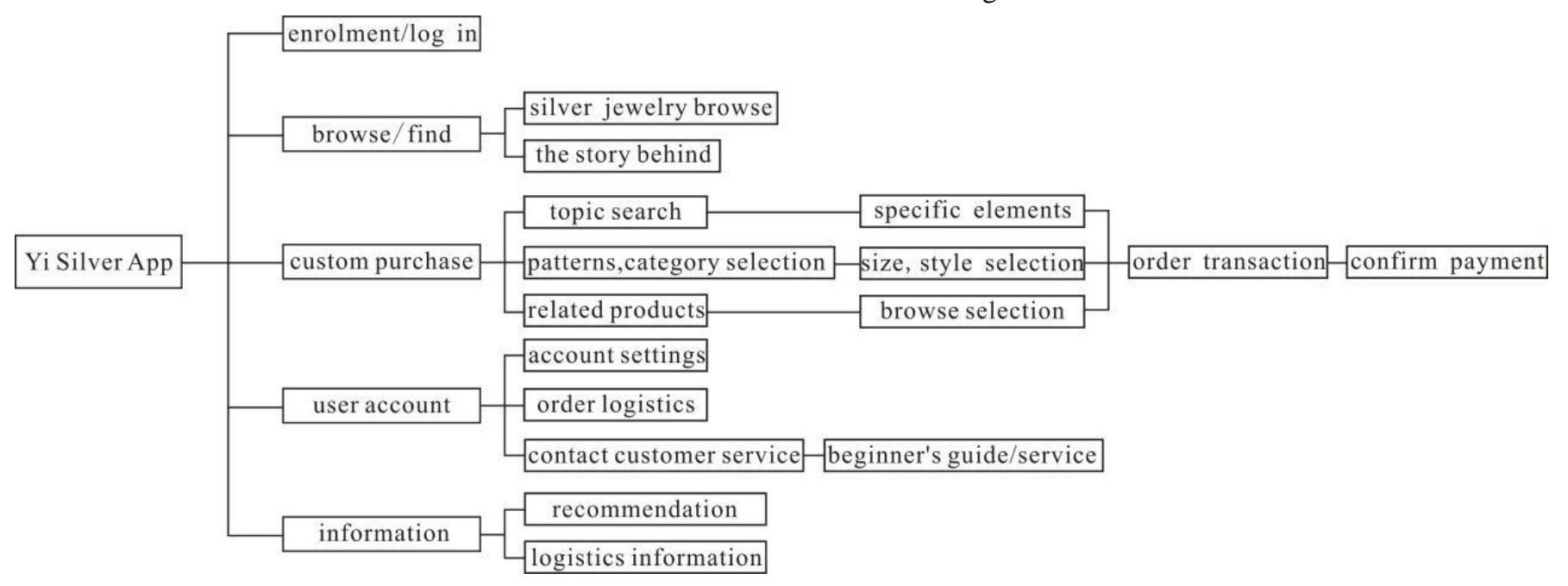

\section{ANALYSIS OF APP USERS OF QIANG PEOPLE'S SILVER JEWELRY}

The user experience refers to the related psychological feelings of emotions, beliefs, cognition and preference generated during the interaction process when users experience products or enjoy services. Combining the design of the APP interface with the patterns of the Qiang people's silver jewelry, the pattern is converted into emotional symbols, to reduce the user's cognitive load. Through research and analysis, the user experience design aspect of the Qiang people's silver jewelry APP can be modeled by the following points: function simplification, pattern recognition and color orientation.

\section{A. Function Simplification}

As a cultural inheritance APP for the productive protection of the Qiang people's silver jewelry, the Qiang people's silver jewelry APP should utmost show the beauty of the traditional handicraft techniques of the Qiang people's silver jewelry, remove the useless pictures and text, simplify the use flow of the APP, enhance its practicality, reduce the cost of user learning, and meet the needs of users to a great extent. The main functional diagram of the APP is shown below in "Fig.1".

Fig. 1. The main function of the APP.

\section{B. Visual Design}

The representation system and associative thinking of human memory are based on the real world[6]. The design of APP interface should be imaginative and universal, considering the cognitive unity under different cultural backgrounds, and use the combination of graphic and textual to express. If in the user experience process, the user needs to find out how to differentiate functions, it is very easy to let the user feel bored. Therefore, the pattern of APP design should be produced as representative and original as possible, and integrate the colors and patterns with ethnic characteristics of the Qiang people into the interface design of the APP, so as to be remembered easily, give user a more comfortable and smooth interactive experience, and leave the user a deep impression in product experience.

\section{Color Orientation}

Color has a direct impact on people's cognition and emotions. In general, color conveys information faster than words. Matching the emotion symbol represented by the color with the human emotion mode can effectively reduce the user's cognitive error rate, such as white is one of the main characteristics of the Qiang people[7]. There is a saying: "white for joy and white for good", the Qiang people adore white greatly; The Qiang people also like red color, taking the red color as the mascot, hanging red is the highest traditional etiquette of the Qiang people, which is known as upholding red custom. Therefore, the APP interface design should highlight the characteristics of the product as much as possible to make the user obtain emotional satisfaction during the experience process. 


\section{APP INTERFACE DESIGN}

The essence of smart phone APP interface is a cognitive metaphor[8]. As an internet product, the Qiang people's silver jewelry APP should investigate and analyze the existing products on the market before designing. Through investigation, it is found that there are few APP interface designs related to the productive protection of the Qiang people's silver jewelry. The Qiang people's silver jewelry, as a non-material cultural heritage, with its diverse varieties, beautiful shapes and exquisite craftsmanship, not only presents people with a magnificent and colorful art, but also displays a spiritual world with rich connotations, but it cannot be connected with the times and does not have a good connection with the current consumption patterns. Therefore, it concludes and summarizes from the aspects of functions, visual and emotional experiences of APP. Judging from existing APP on the market, the content labels of these product are classified cluttered and unreasonable, ignoring the user's experience and cognitive psychology.

\section{A. Functional Orientation}

The architecture design means that the interface design process determines the function, settings and features of the APP interface design to a certain extent, combing the user's experience process, and arranging and connecting the functions and the user interfaces. After the user browsing the content of the story, it presents a series of production processes and unique creative designs, to stimulate the user's interest in related products. Therefore, the interface interaction should be humanized. In addition, the operation experience should be diversified. The operation feedback is an instruction or response to the operation behavior of the user, which makes user understand the current operation status and operation consequences. The system feeds back the operation result through dialog boxes, voice prompts and other methods [9]. The architecture diagram of the APP shows the connections and differences between the interfaces, which provides the basis for the interface design in the later stage, enhances the ease of use and practicality of the APP, and enhances the user's interactive experience and cognitive psychology, as shown below in "Fig. 2".

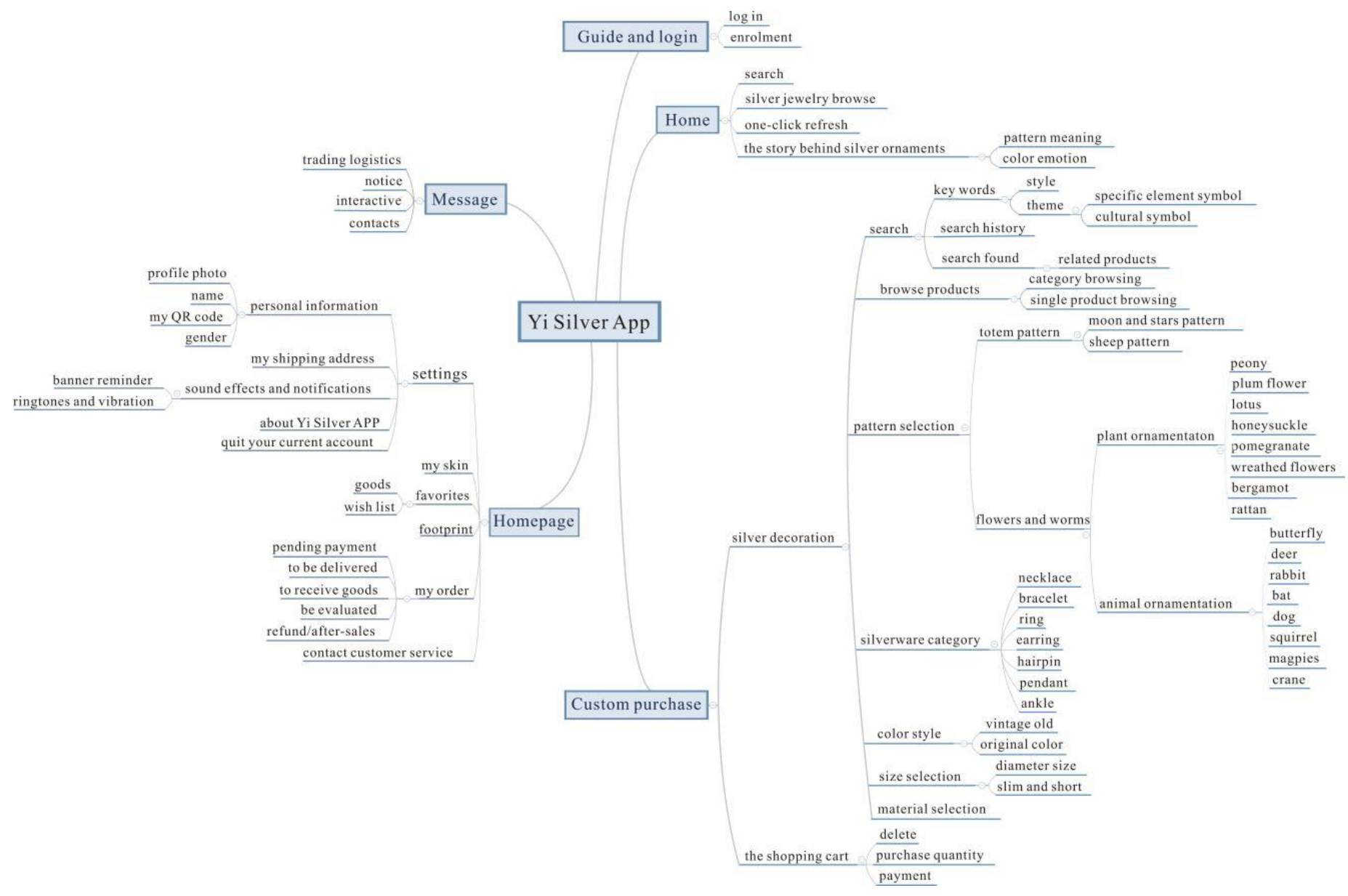

Fig. 2. The frame of the APP.

\section{B. Visual Presentation}

Visual presentation should be rationalized. The purpose of the design is not only the visual effect of the work, but also the practicality of the work, which must be designed and arranged according to the target user's cognitive characteristics and the demands for the product. It likes that azalea symbolizes wealth and peace, love purity, family 
harmony, and also allow users to think of that period of beautiful love story in the browsing process. The visual effect also directly leads to the final effect of product identification. The design of the APP interface must be able to stimulate the user's desire and enthusiasm for using, so that the products and people can communicate with each other. The representative patterns - azalea, peony, pomegranate and lotus, etc., are converted into function keys to help users identify and memorize, then reduce the distance sense with the user. The overall interface is color-unified, to achieve simple results and follow people's visual laws in "Fig. 3".

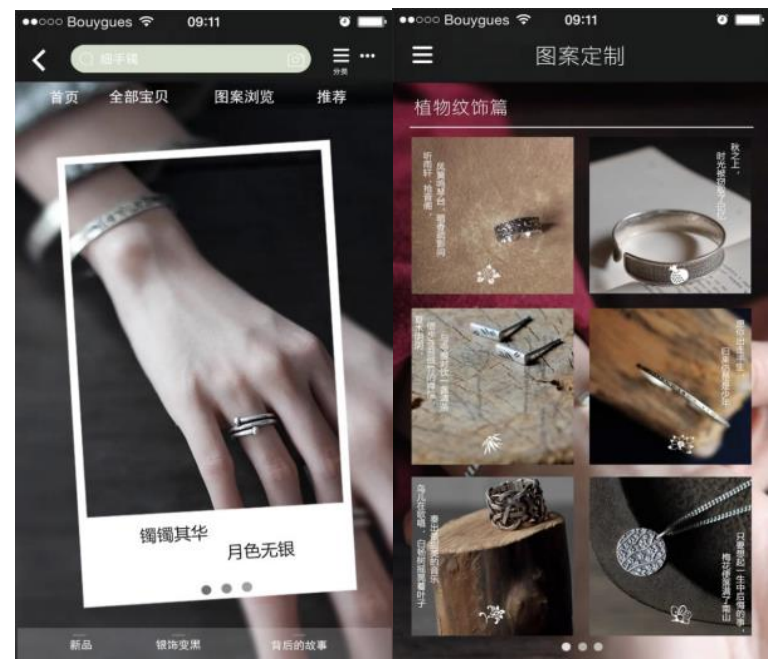

Fig. 3. The interface of the APP.

In order to reduce the puzzle of user experience, the element symbols are used to represent the specific Qiang people's silver jewelry pattern in the custom parts of the silver pattern, to enhance the recognition of the silver jewelry. Such as: plum: together with the magpie symbolizes happiness appearing in one's face. Pine, bamboo and plum together means three friends of winter; bergamot: means longevity; bamboo: peace bamboo, rich bamboo, bamboo reporting peace or rising steadily; pomegranate: pomegranate opens with one hundred, more children and more happiness, etc. Converting the text into visual symbols can enhance the user's goodwill for the product and make the communication between the user and the product smoother.

\section{Emotional Expression}

Emotional expression must be diversified. Every silver product of the Qiang people is a rare handicraft. The colors selected in the APP interface design, such as the representative colors of white and red, which enable the user to achieve the results of easy-to-recognize and easy-tomemorize during the experience process. For example, azalea would remind users with that beautiful love story, then the user wants to customize the jewelry with azalea pattern to commemorate their love; Leather bag, would make people think of its rich ancient atmosphere and vicissitudes of life, as if feeling the scene that the deaf people wore skins to go out and hunt in ancient times; At the same time, it shows the story behind the handicrafts of the Qiang people silver jewelry, thus to achieve the emotional resonance between the product and the user in "Fig. 4".
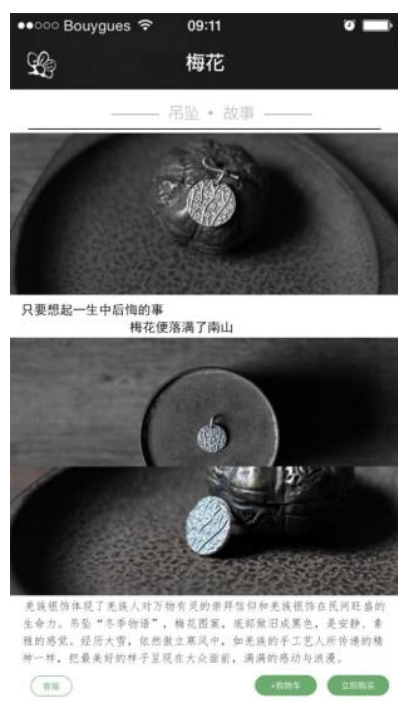

Fig. 4. The interface of the APP

\section{CONCLUSION}

With the vigorous promotion of the policy "Internet +", people's demand for traditional culture is gradually increasing. In the future, the design of the traditional cultural APP interface is not only satisfied with users, but the old carrier form cannot attract the use groups in the current mainstream. It should conduct more in-depth research through user experience and user cognitive psychology, so as to give users a better interactive experience. In the future, during the research process on the design of Qiang people's silver jewelr APP interface, it will continue to deepen and innovate in this basis, in order to provide more reliable evidence for improving the user's interactive experience.

\section{ACKNOWLEDGMENT}

This paper is funded by the research center of Qiang people (QXZ1605); teaching reform program of Sichuan Normal University.

\section{REFERENCES}

[1] McGuire Dennis. McGuire Mass Communication Theory [M] Shandong People's Publishing House, 2006

[2] Robert J. Sternberg. Cognitive Psychology [M]. Beijing: China Light Industry Press, 2016

[3] Liu Xiuzhen, Ding Jianpeng. The Affordance Research on APP Interface Design of Smart Phone [J]. Packaging Engineering, 2017, 38 (22):135-140

[4] Donald A. Norman. Emotional Design [M]. HE Xiaomei, OU Qiuxing, translated. Beijing: CITIC Press, 2015.

[5] Chamorro-Koc Marianella, Popovic Vesna, Emmison Michael. Human experience and product usability: principles to assist the design of user-product interactions. [J]. Applied Ergonomics, 2008, 40(4):648-656. 
[6] TENG Zhaoxuan, Jin Songwen, Zhen Yongliang. The Visibility of Icon in Graphical User Interface of Mobile Phones [J].Packaging Engineering, 2013,34(04):66-70.

[7] Gao Yujiao, Qin Jingyan, Tao Jin. Visual Perception of Dynamic Color in Mobile APP Interactive Design [J]. Packaging Engineering, 2016,37(08):134-137.

[8] Xu-xin. Usability research of metaphor design in graphic user interface [D]. Zhejiang Gong shang University, 2012.

[9] Liu Xiaolu, Ding Hongyue, Wei Xinzhu. Research on the Design Of Information APP Interface Based On The Model Of Cognitive Needs For The Elderly [J]. Design, 2018, (01):26-27. 